\title{
ESTUDOS DA LEITURA NO LIVRO DIDÁTICO DE LÍNGUA PORTUGUESA DOS ANOS INICIAIS DO ENSINO FUNDAMENTAL
}

\section{READING STUDIES IN THE PORTUGUESE LANGUAGE TEXTBOOK OF THE EARLY YEARS OF ELEMENTARY SCHOOL}

\author{
Maria de Fátima Xavier da Anunciação de Almeida ${ }^{1}$
}

\begin{abstract}
Resumo: Neste artigo apresentamos um panorama de estudos sobre o livro didático de língua portuguesa para os anos iniciais do ensino fundamental, produzidos em Programas de Pós-Graduação em Educação e Letras no país. O corpus da pesquisa são as produções acadêmicas de 2010 a 2019, identificadas no Catálogo de Teses e Dissertações da Capes/MEC. Trata-se de um levantamento bibliográfico para mapear os estudos realizados sobre o tema, para compor a primeira fase de investigação que vem sendo desenvolvida junto ao Grupo de Pesquisa ALLEAULA/FE/UNICAMP, cujo objetivo principal é compreender as práticas e as representações de leitura, construídas e significadas nos livros didáticos de língua portuguesa, que compõem a Coleção Ápis, aprovada pelo PNLD 2019. Entre outros resultados, a pesquisa aponta que praticamente são inexistentes os estudos que analisam a materialidade dos livros didáticos em seus circuitos de produção, circulação e de recepção, polos distintos que dão movimento e sentidos a esses objetos, em determinada comunidade cultural (a escolar), outra opção para o campo de pesquisa.

Palavras-chave: Leitura; livro didático; língua portuguesa.
\end{abstract}

\begin{abstract}
In this article we present an overview of studies on the Portuguese language textbook for the early years of elementary school, produced in Graduate Programs in Education and Letters in the country. The corpus of the research are the academic productions from 2010 to 2019, identified in the Catalogue of Theses and Dissertations of Capes/MEC. This is a bibliographic survey to map the studies carried out on the subject, to compose the first phase of research that has been developed with the ALLEAULA/FE/UNICAMP Research Group, whose main objective is to understand the practices and representations of reading, constructed and signified in the Portuguese-language textbooks, which make up the Ápis Collection, approved by PNLD 2019. Among other results, the research points out that there are practically no studies that analyze the materiality of textbooks in their production, circulation and reception circuits, distinct poles that give movement and meaning to these objects, in a given cultural community (the school community), another option for the field of research.
\end{abstract}

Keywords: Reading; textbook; portuguese language.

\section{Apresentação e propósitos}

Apresentar um panorama de estudos produzidos nos Programas de Pós-Graduação em Educação e Letras ${ }^{2}$, no país, sobre o livro didático de língua portuguesa dos anos iniciais quando tematizam a leitura, é o enfoque deste texto. Nesse caminho, tivemos por corpus da pesquisa as produções acadêmicas defendidas no período de 2010 a 2019, identificadas no repositório Catálogo de Teses e Dissertações da Capes/MEC.

\footnotetext{
${ }^{1}$ Universidade Federal de Mato Grosso do Sul, Campo Grande, MS, Brasil; Universidade Estadual de Campinas, Campinas, SP, Brasil.

${ }^{2}$ Agradecimento especial à Profa. Norma Sandra de Almeida Ferreira/ALLEAULA/UNICAMP, supervisora do nosso estágio de pós-doutorado, pelas preciosas contribuições a este trabalho.
} 
A ideia é mapear pesquisas realizadas sobre o tema, para compor investigação que vem sendo realizada junto ao Grupo de Pesquisa ALLEAULA/FE/UNICAMP, em vista de estágio Pósdoutoral em Educação, cujo objetivo principal é compreender as práticas e as representações de leitura construídas e significadas para o livro didático do componente língua portuguesa dos anos iniciais do ensino fundamental, dentro da Coleção Ápis, aprovada no PNLD 2019.

Vários estudos já colaboraram para a construção de um campo de conhecimento sobre o livro didático, como os de Bittencourt (1993); Munakata (2012), Moreira (2011, 2012), Teixeira (2013), Mortatti, Oliveira e Pasquim (2014), André (2011), Batista (2007), Rojo e Batista (2003) e de Rojo (2010), para citar alguns. São pesquisadores interessados em produzir um "estado do conhecimento" de pesquisas acadêmicas sobre determinada temática ou construir uma história do livro didático voltado para o ensino de História, de Língua e de Literatura, de alfabetização, entre outros.

Muitos desses estudos, nas últimas décadas, vêm acompanhando, não de forma neutra, o que foram e estão sendo produzidos nos contextos social, histórico, cultural, político e educacional no país. Buscam compreender o livro didático historicamente datado e em sua multifaceta e complexidade, buscando atender a interesses de uma esfera de produção e de circulação (BUNZEN, 2005; BUNZEN, 2009) e a uma específica comunidade de leitores. Além disso, destacam que o livro didático pode ser ainda estudado como um instrumento pedagógico, que reflete as várias tradições, as inovações e as utopias de uma época. (BUNZEN, 2005, p. 18 - Grifos do autor.).

Bittencourt (1993), Munakata $(1997,2012)$ e Moreira $(2011,2012,2017)$ apontam que o campo de pesquisa, na área, inicia-se na segunda década de $1950^{4}$. Desde então, as pesquisas crescem e se expandem por diferentes campos de conhecimento (história, educação, letras, matemática, geografia, física, etc.), possuindo múltiplas análises teórico-metodológicas e temáticas investigativas.

Segundo Munakata (2012), nos anos de 1970 e 1980 as produções não passavam de 50 títulos. "Destes, uma parcela significativa destinava-se a condenar a ideologia (burguesa) subjacente aos livros utilizados na escola (MUNAKATA, 1998)". (MUNAKATA, 2012, p. 181). Após esse período, é expressivo o seu crescimento nos anos de 1990 e 2000, investigando o livro didático, ora como fonte, ora como objeto de pesquisa, ou ainda, articulando esses dois vieses.

Para Circe Bittencourt (1993), a ampliação do campo de estudos do livro didático (LD) no país, ampliou novas vertentes teóricas, incorporando “[...] aportes da história do currículo e das disciplinas escolares, da história cultural e da história do livro e da leitura. Organizaram-se centros e grupos de pesquisa; promoveram-se projetos e eventos sobre o tema, no âmbito brasileiro e internacional, " (MUNAKATA, 2012, p. 179) criou-se uma rede de pesquisadores interessados neste material como documento a ser inquerido de forma multidisciplinar.

Conforme Munakata (2012), no século XXI, os estudos dão um salto quantitativo ${ }^{5}: 800$ trabalhos são produzidos de 2001 a 2011, tornando-se difícil mensurar a quantidade deles, pois esse número pode ter sido muito maior. A quantidade exponencial se deve ao fato de que

[...] começaram se organizar eventos específicos sobre o tema, caso do Simpósio Internacional "Livro Didático: Educação e História", realizado na Universidade de São Paulo, em 2007; sessões especiais sobre o tema passaram a ser abrigadas nos eventos das grandes áreas. Centros, núcleos e projetos de pesquisa sobre o tema também foram se constituindo nos programas de pósgraduação das diferentes áreas (educação, letras, história, matemática etc.). (MUNAKATA, 2012, p. 181)

\footnotetext{
${ }^{3}$ Ver Ferreira $(1994 ; 1999 ; 2002 ; 2011 ; 2018)$, que vem produzindo pesquisas sobre esse tipo de trabalho, no campo da Leitura, tomando como fontes teses de doutorado e dissertações de mestrado defendidas no Brasil.

${ }^{4}$ Sugerimos, para o aprofundamento do tema, consultar Moreira $(2011,2012,2017)$.

${ }^{5}$ Ver melhores detalhes em Munakata (2012).
} 
Nesse contexto, as pesquisas sobre a história do ensino da leitura e da escrita, dos manuais escolares na educação primária, os quais vêm recebendo, ao longo do tempo, diferentes denominações no Brasil: cartilhas, livro didático de alfabetização e/ou de letramento e, atualmente, livro didático de língua portuguesa ${ }^{6}$ também vão sendo produzidas (MORTATTI, 2000, 2006; TEIXEIRA, 2014; MACIEL, 2000, etc.), com ênfase, para os anos iniciais de escolaridade, no esforço de colaborar para uma melhor qualidade da escola.

Diante do cenário de estudos do livro didático apresentados, assumimos em nossa pesquisa que o livro didático de língua portuguesa dos anos iniciais (LDLP) é um objeto cultural que faz parte da "[...] cultura no âmbito produzido pela relação interativa entre "[...] práticas e representações. (BARROS, 2004, p. 76)

Tanto os objetos culturais seriam produzidos "entre práticas e representações", como os sujeitos produtores e receptores de cultura circulariam entre esses dois polos, que de certo modo corresponderiam respectivamente aos 'modos de fazer' e aos 'modos de ver'. (BARROS, 2004, p. 76).

O LDLP entendido como objeto da cultura escrita (CHARTIER, 1990) tem como característica uma materialidade que lhe dá concretude e uma forma de linguagem que o constitui como um gênero discursivo (BAKHTIN, 2003), em seu sentido mais amplo:

Todos os diversos campos da atividade humana estão ligados ao uso da linguagem. Compreende-se perfeitamente que o caráter e as formas desse uso sejam tão multiformes quanto os campos da atividade humana, o que, é claro, não contradiz a unidade nacional de uma língua. O emprego da língua efetuase em forma de enunciados (orais e escritos) concretos e únicos, proferidos pelos integrantes desse ou daquele campo da atividade humana. Esses enunciados refletem as condições específicas e as finalidades de cada referido campo não só por seu conteúdo (temático) e pelo estilo de linguagem, ou seja, pela seleção de recursos lexicais, fraseológicos e gramaticais da língua, mas, acima de tudo, por sua construção composicional. Todos esses três elementos - o conteúdo temático, o estilo, a construção composicional - estão indissoluvelmente ligados no todo do enunciado e são igualmente determinados pela especificidade de um determinado campo da comunicação. Evidentemente, cada enunciado particular é individual, mas cada campo de utilização da língua elabora seus tipos relativamente estáveis de enunciados, os quais denominamos gêneros do discurso. (Itálico do autor, p. 262-262).

Nesse sentido, o LD é produzido em condições específicas que indissoluvelmente estão inscritas no campo em que ele circula, pelos propósitos para os quais é criado, pelos leitores para os quais são predestinados e, ainda, pelas vozes (BAKHTIN, 2003) que (em tensão) o constituem e lhes dão forma.

Segundo Ferreira (1999), o livro didático seria então caracterizado como:

[...] um produto intelectual, que se concretiza num certo suporte de material, que envolve não só o autor e o leitor, mas diferentes pessoas que se incumbem de re(organizar) um conjunto de impressão, distribuição e circulação dessa

\footnotetext{
${ }^{6}$ Os livros didáticos voltados ao ensino inicial da leitura e da escrita, a partir da homologação da Base Nacional Comum Curricular - BNCC - do ensino fundamental e PNLD 2019, vão receber a denominação do componente curricular proposto pela BNCC: Língua Portuguesa. Desse modo, unificou a denominação do componente curricular de cada livro das coleções didáticas voltadas ao ensino da língua materna, nos anos iniciais do ensino fundamental.
} 
mercadoria. Uma mercadoria, que como tal, é objeto de produção e de consumo e de recepção. (FERREIRA, 1999, p. 2).

Sustentado por determinado suporte impresso ${ }^{7}$, o livro didático está intimamente ligado às condições materiais, técnicas, editoriais que produzem a necessidade de sua importância, subordinada aos interesses e necessidades da escola e das políticas públicas em educação. No nosso caso, pretendemos contribuir com os estudos sobre o livro didático de língua portuguesa (LDLP), tomando como objeto de pesquisa a leitura nos anos iniciais do ensino fundamental, entre práticas e representações culturais.

Segundo Ferreira (2008), a temática da leitura, nesses quarenta anos, tem movimentado e mobilizado uma comunidade crítica que avança nos estudos, de forma quantitativa e diversificada, em distintas perspectivas teórico-metodológicas, sob enfoques disciplinares ou multifacetados. De fato, a leitura tem sido objeto de investigação de campos científicos que se cruzam, se complementam ou se distinguem diante de uma problemática bastante complexa que desafia os pesquisadores, em várias direções e aspectos.

Os estudos têm apontado que a leitura pode ser (re) significada - em suas condições de produção no tempo e espaço - pelos seus autores (escritores, livreiros, editores, leitores), pelos seus espaços de guarda, de produção, de divulgação ou de circulação (livrarias, editoras, escolas, mídia), pelos seus suportes e materialidades (impressos, digitais, manuscritos, pergaminhos), pelas suas práticas e pelos seus usos, próprios de diferentes comunidades de leitores (religiosa, familiar, escolar).

Nesse sentido, esta pesquisa é orientada pela perspectiva trazida pelos estudos da História Cultural. Apoiamo-nos na leitura como prática cultural, realizada em diversos suportes e suscetível a diferentes gestos, espaços e hábitos, passível a diferentes apropriações e avaliações, enfatizando a impossibilidade de que seja retratada em configuração abstrata e universal. (CHARTIER, 1990). Apoiamo-nos, assim, na compreensão da leitura como representação diferentemente construída pelos sujeitos que dão sentidos e valores a diferentes usos da linguagem, produzem modalidades (partilhadas e singulares) de ler, em diferentes contextos da atividade humana, inclusive o escolar. Consideramos que uma pesquisa que busca compreender a leitura no livro didático deve considerar colocar que essa prática (a da leitura) se situa entre uma liberdade condicionada ${ }^{8}$ - por uma verdadeira maquinaria conduzida pelo autor, editor, mercado e tradição nos campos pedagógicos, políticos, econômicos e editoriais - e uma disciplina derrubada - pelos leitores com seus distintos usos, competências e disposições específicas, expectativas e interesses (CHARTIER, 1990).

\footnotetext{
${ }^{7}$ Como sabemos, o LD é um objeto multifacetado que assume social e culturalmente diferentes formas e suportes ao longo da sua história. Atualmente, por exemplo, podemos identificar livros didáticos digitais e acessados online. Neste artigo, porém, faremos referência apenas ao material impresso tal como o nosso objeto de estudo se apresenta na Coleção em estudo.

${ }^{8}$ Segundo Chartier (1990), um dos modelos de compreensão para explicar os textos, os livros e suas leituras pressupõe dois dispositivos que devem ser manejados juntos: disciplina e invenção. Para o autor, todo o dispositivo que busca controlar e garantir os sentidos pretendidos no polo da produção, carrega também usos que o subvertem e os (re) reinventam, por parte dos seus leitores. Conforme Chartier (1990), não há produção cultural que não empregue materiais impostos pela tradição, pela autoridade ou pelo mercado e que não esteja submetida às vigilâncias e às censuras de quem tem poder sobre as palavras ou gestos. Por outro lado, são incontroláveis as apropriações e os usos sempre inusitados dos leitores de carne e osso, em diferentes condições concretas de leitura. Assim, inquerir pela leitura inscrita, nos livros didáticos, é reconhecer os modos como se articulam os condicionamentos intencionalmente planejados no polo da produção e os usos sempre singulares por parte dos leitores.
} 


\section{Caminhos metodológicos e composição do corpus}

Ao buscar construir uma visão geral e específica da produção acadêmica sobre leitura, no livro didático de língua portuguesa, para os anos iniciais, enveredamos por um levantamento de teses de doutorado e dissertações de mestrado disponíveis no repositório da Capes, no período de 2010 a 2019. A ideia é que um levantamento bibliográfico sobre leitura nos ajuda não só compor um panorama atual desta produção, mas ainda, colabora para a compreensão dos modos como a leitura se distribui e se organiza no campo em: diferentes ênfases ou as ausências temáticas; tendências teóricas e metodológicas; temas dos estudos que se aproximam e se distanciam de nosso foco investigativo etc.

Nesse artigo, apoiado em nossa pesquisa sobre os livros da Coleção Ápis de Língua Portuguesa dos anos iniciais do ensino fundamental, colocamos as seguintes questões: o quanto este levantamento bibliográfico poderá contribuir para o debate da leitura inscrito nos livros didáticos atuais? Como se situa nosso trabalho no campo acadêmico já constituído sobre esta temática?

Em uma primeira identificação e seleção para a construção do mapeamento da produção acadêmica sobre leitura, iniciamos uma busca no Catálogo de teses de doutorado e dissertações de mestrado, da Capes, a partir do termo livro didático. Nessas primeiras buscas, localizamos, no período de 1987 a 2019, um conjunto bastante volumoso que totalizou 23.784 trabalhos defendidos em diferentes programas de pós-graduação em: Educação, Letras, Filosofia, História e Matemática, entre outros.

Diante do volume de estudos, optamos por realizar o levantamento apenas nos Programas de Pós-graduação em "Educação" e "Letras", pois consideramos que essas duas áreas, por tradição, têm um significativo interesse na investigação de livros didáticos ligados à disciplina de língua portuguesa. E ainda, optamos por essas áreas porque estão relacionadas com as áreas de formação desta autora. Mesmo considerando que a produção da temática de nosso interesse esteja presente em outros lócus de pesquisa com larga tradição, optamos por delimitar nossa busca, excluindo, por exemplo, os Programas de pós-graduação stricto sensu em Linguística; Linguística Aplicada, Psicologia, etc., assim como os Trabalhos de Conclusão de Curso de graduação ou da pós-graduação a nível lato sensu.

Também delimitamos a busca dentro do período 2010 a 2019, focando na identificação dos trabalhos defendidos a quase uma década. Essas exclusões foram orientadas por opções que nos ajudassem a delimitação na composição do corpus, em um volume de trabalhos e um limite do tempo plausíveis para o desenvolvimento de nossa investigação.

Sob esses critérios, numa segunda etapa, novamente procuramos pelos termos livro didático e leitura no repositório da Capes e localizamos um conjunto de 3.743 produções acadêmicas das áreas de Educação e de Letras, no período de 2010 a 2019. Organizamos a quantidade de dissertações de mestrado e de teses de doutorado, elaborando uma tabela em que essa produção pudesse ser identificada pela área e pelo ano de defesa de cada uma delas, ao longo do período. Desse modo os dados foram organizados e os descrevemos para o leitor.

Foi possível localizar 2.253 pesquisas nos programas de "Educação", distribuídas em 1.655 dissertações de mestrado 9 e 598 teses de doutorado. As demais, 1.490 produções estão localizadas no programa de "Letras"10, das quais 883 são do mestrado acadêmico e 607 do mestrado profissional.

Assim, os dados apontam visivelmente para uma maior quantidade de interesse pela temática por parte dos pesquisadores, no nível de mestrado em relação aos de doutorado. Apontam ainda

\footnotetext{
${ }^{9}$ No repositório da Capes, os trabalhos acadêmicos dos mestrados profissionais da área da educação não se encontram denominados como tal; são identificados no rol dos mestrados acadêmicos.

${ }^{10}$ Não localizamos nenhuma tese de doutorado em "Letras" no recorte temporal da investigação.
} 
que o interesse se mantém tanto nos mestrados acadêmicos quanto nos da categoria profissional, uma categoria bastante recente nos programas de pós-graduação, no nosso país.

Inventariado e organizado em forma de tabela, do conjunto de 3.743 trabalhos de defendidos, nos programas de Letras e Educação, ao longo de 2010-2019, nós fizemos novas leitura(s) cuidadosa (s) de cada um dos seus títulos e resumos com o intuito de selecionar aqueles que trouxessem como temática/assunto principal: a leitura, no livro didático de Língua Portuguesa (LDLP) dos anos iniciais de escolaridade. Nesse inventário foi necessário excluir a grande maioria das pesquisas acadêmicas que investigavam temas como "alfabetização" ou "letramento"; "ensino da leitura e da escrita"; "literatura"; "produção escrita de texto", "gramática" ou "estudos linguísticos" etc., e também, as pesquisas sobre livros didáticos que eram exclusivamente de outras disciplinas, como História, Geografia etc., que não incluíam os de Língua Portuguesa, pois não atendiam aos objetivos de nossa investigação.

Pelo fato de não localizarmos trabalhos acadêmicos que estudam o LDLP, dos anos iniciais do ensino fundamental, dentro do referencial teórico da História Cultural que tinham por foco os estudos de sua materialidade dentro da cultura escrita, no circuito que se movimenta entre os polos da produção, circulação e da recepção/consumo, e ainda, em que a abordagem da leitura se configure entre as práticas e as representações de seus leitores, adotamos por critério apresentar o movimento do processo de seleção que culminou em apenas 21 trabalhos selecionados para a interlocução.

Mapeados todos os dados que interessam à temática da pesquisa, selecionamos do conjunto formado por 3.743 produções acadêmicas, apenas 21 trabalhos. Uma quantidade bem menor do que tínhamos expectativas de encontrar. Esse pequeno corpus de 21 pesquisas foi composto por trabalhos que: 1. Abordam a temática "leitura" quer associada à escrita, nos momentos iniciais da escolaridade, quer "leitura" como objeto de investigação distinto da alfabetização; 2. Voltam-se para os primeiros anos ou mais avançados anos de escolaridade; 3 . Trazem de forma explícita ou não "referências teórica e metodológica", entre elas a da História Cultural; 4. Analisam coleções de livros selecionando ou não a coleção "Ápis". Os critérios adotados para essa seleção permitiram organizar o corpus, de forma a incorporar tais estudos no nosso trabalho na discussão quanto à temática, ao aprofundamento da teoria e metodologia empregadas na análise, ou ainda, à comparação entre coleções ou anos de escolaridade abordados pelos autores, entre outros.

\section{A produção acadêmica sobre a leitura no livro didático de língua portuguesa}

Após a localização e a seleção de 21 trabalhos defendidos nos programas de pósgraduação de "Educação" e "Letras", que tratam da temática, novamente fizemos diversas leituras dos títulos e resumos; algumas vezes, recorremos ao texto integral ou parcial das dissertações de mestrado e das teses de doutorado. A(s) leitura(s) foram guiadas pela nossa intenção em identificar aqueles trabalhos que, de alguma forma, dialogam com a nossa pesquisa ou se aproximam do nosso interesse (teórico-metodológico) investigativo.

O corpus formado por esses 21 trabalhos trouxe a seleção de investigações da produção acadêmica sobre a leitura e o LDLP, com ênfases quanto a alguns pressupostos teóricos e metodológicos, temáticas e anos de escolaridade. Organizamos, em seguida, um quadro, que se encontra em arquivo pessoal da autora, reunindo esses 21 trabalhos $^{11}$, destacando os dados

\footnotetext{
${ }^{11}$ As produções acadêmicas descritas no Catálogo de Teses e Dissertações da Capes podem ser acessadas - resumos e até os arquivos completos em PDF, somente a partir de 2013. Antes desse período, não é possível localizá-los, uma vez que neste ano, houve a implantação da Plataforma Sucupira, que se tornou a fonte principal de lançamento desses dados e tem alimentado o referido repositório. O pesquisador precisará recorrer ao acervo da Biblioteca Digital de Teses e Dissertações - BDTD, do Ministério da Ciência e Tecnologia, caso necessite acessá-las.
} 
como instituição, programa de pós e ano de defesa do trabalho; título e temática da pesquisa; nomes dos autores e da fonte (banco de dados).

As pesquisas organizadas nesse quadro foram distribuídas uma a uma, em uma sequência cronológica dentro do período de 2010-2019. Assim, podemos afirmar que a área da Educação apresenta maior periodicidade e maior número de produções (17) do que a de Letras (4). Localizamos em Educação: 3 produções em 2010; 2 produções em 2011; 2 produções em 2012; 5 produções em 2014; 1 produção em 2015; 2 produções em 2016; 1 produção 2017 e 2018. Sentimos ausência de produções acadêmicas, na área, nos anos de 2013 e 2019. Em Letras não ocorre essa regularidade de pesquisas entre o período do tempo e a quantidade de trabalhos, as produções apresentadas são bem menores: apenas 1 produção em 2011, 2012, 2015, 2017 e nenhuma no ano de 2019. Também, sentimos a ausência de produções na área referentes aos anos de 2010, 2013, 2014, 2016, 2018 e $2019^{12}$.

Da leitura do título e resumo de cada trabalho, criamos o que denominamos por "enunciados temáticos", considerando as ênfases explicitadas pelos seus autores sobre as intenções investigativas, de forma mais resumida, enfatizando o objetivo da investigação, a fonte da pesquisa (identificação do livro didático e os anos previstos por ele) e a perspectiva teórica, quando explicitada pelo autor e expressa no resumo do trabalho. Buscamos nos enunciados temáticos pistas dos aspectos de maior interesse dos pesquisadores em sua abordagem da "leitura", inquerida como objeto de conhecimento.

Metodologicamente, esses enunciados produzidos, um a um, a partir de cada título e resumo dos trabalhos, nos permitiram construir uma rede de comunicação verbal da esfera acadêmica (FERREIRA, 2001), interrogando-a pelos vários fios que a compõem dependendo do ponto de partida que se estabelece em cada texto. Assim os enunciados temáticos ganharam nuances que ora aproximavam um trabalho do outro, ora se distanciavam, ou ainda, se repetiam conforme inferíamos a preocupação principal do pesquisador por determinado olhar. Todas elas em comum trouxeram a "leitura" (nos livros didáticos de língua portuguesa) como a temática principal, objeto de nosso interesse na composição do corpus do trabalho. Mas esses enunciados vieram combinados com o interesse do pesquisador também pela "escrita", ou por anos que não os iniciais do Ensino Fundamental I, ou ainda, por uma escolha de outro livro que não o que selecionamos para nossa pesquisa.

A ideia consistiu em (re) ler essas informações buscando aproximar as pesquisas ou as distanciar umas das outras em uma rede dialógica (não linear) entre os enunciados, convocando a temática como objeto de conhecimento, combinada com a abordagem teórica metodológica, ou ainda, com a especificidade do documento (livro didático para determinado ano, em determinada disciplina e coleção).

\section{Uma primeira aproximação dos estudos: pelo público leitor}

No interior do corpus de 21 pesquisas selecionadas dos programas em "Educação" e "Letras", 16 delas podem ser agrupadas de acordo com o interesse dos pesquisadores por livros didáticos destinados ao público escolar. Livros produzidos para usos nos primeiros anos iniciais do ensino fundamental são 10: Kikuchi (2010); André (2011); Silva T. (2012); Nascimento (2012); Campos (2014); Godinho (2014); Silva A. (2016) e Araújo (2017); Teixeira (2014) e Rodrigues (2018). Apenas 02 trabalhos voltam-se para livros didáticos do $5^{\circ}$ ano do ensino fundamental (SILVA, 2014 e LUZ, 2015); 01 única pesquisa analisa uma coleção de livros de

\footnotetext{
${ }^{12}$ Essa ausência de registro de pesquisa, nos programas de Letras e de Educação, especificamente no ano de 2019, talvez possa ser explicada pela demora dos trâmites entre a defesa do trabalho e a disponibilidade nos bancos de dados da produção acadêmica aos usuários em geral.
} 
língua portuguesa, do $1^{\circ}$ ao $5^{\circ}$ ano (SILVA G, 2016) e mais 01 estuda livros destinados aos alunos do ensino médio (NASCIMENTO, 2017). Nesse corpus, ainda encontramos 01 trabalho que traz quatro manuais dos professores referentes a livros didáticos dos primeiros anos (SILVA C., 2012) e mais 01 sem especificação.

A escolha dos pesquisadores recai, assim, prioritariamente para os livros didáticos ligados ao momento da alfabetização e letramento, na escola, representada praticamente pela metade da quantidade de trabalhos (10) do total selecionado pelo corpus.

Essa predominância de investigações sobre o LDLP destinados aos alunos dos $1^{\circ}$ e $2^{\circ}$ anos iniciais do ensino fundamental, em que a preferência é para trazer estudos da leitura junto à escrita no processo de alfabetização e letramento, talvez sugira a importância atribuída pelos estudiosos à alfabetização no nosso país e a urgência de uma análise crítica do material destinado à fase inicial de aprendizagem da criança. Que livros estão sendo elaborados para os pequenos escolares, que concepções de alfabetização e letramento orientam as atividades propostas e quais usos têm sido feitos pelos professores desse material, são questões que permeiam essas pesquisas.

À medida que nos distanciamos dos primeiros anos de escolaridade, a temática da "leitura" (associada ou não à escrita ou à literatura) rareia, apresentando-se por exemplo em apenas 1 trabalho sobre livro didático do Ensino Médio (NASCIMENTO, 2017) ${ }^{13}$.

De qualquer modo, o livro didático de língua portuguesa destinado "aos alunos" é a preferência de 14 pesquisadores. No entanto, alguns trabalhos trazem estudos combinando o material dos alunos com manuais do professor ou com documentos oficiais e outros materiais complementares, como o de (SILVA C., 2012), ou ainda, investigam obras complementares de acervos do PNLD (ALBUQUERQUE, 2014). Ou então, as análises recaem para toda uma coleção abrangendo livros, por exemplo, do $1^{\circ}$. ano ao $5^{\circ}$. ano, compondo todo o Ensino Fundamental 1 (SILVA G., 2016) ou para várias Coleções aprovadas pelo PNLD 2016 (SILVA A., 2016).

Nesse corpus o que vemos são interesses de investigação, por parte dos pesquisadores, espalhados por livros didáticos, destinados a diferentes anos de escolaridade e dispostos em diferentes coleções, mas que tem como público prioritário os alunos dos primeiros anos de escolaridade. Para esse público, os estudos se voltam com mais preponderância para os usos feitos pelos professores desse material em sala de aula ou para uma análise das propostas dirigidas para o ensino inicial da leitura e escrita. Praticamente inexistentes são os trabalhos que analisam os livros didáticos, no seu circuito de produção, circulação e recepção, polos distintos que dão movimento e sentidos a esses objetos, em determinada comunidade cultural (a escolar), uma outra opção para este campo de pesquisa.

\section{Uma segunda aproximação dos estudos: pelas temáticas privilegiadas pelos pesquisadores}

Quanto à temática, a maioria dos trabalhos aborda a "leitura" em sua relação indissociável com a escrita, isto é, o processo da alfabetização ou do letramento. Sob diferentes concepções, os pesquisadores indagam pelos modos como o ensino da leitura e da escrita se oferece nos textos e nas propostas didáticas nesse material didático.

Autores como André (2011), Nascimento (2012), Godinho (2014) e Araújo (2017) estudam como os livros didáticos de alfabetização propõem o ensino do sistema da escrita alfabética, em seus usos sociais da leitura e da escrita articulados (ou não) à concepção de alfabetização que tem como centralidade o texto como unidade de ensino. Nascimento (2012), por exemplo, analisa o livro didático de alfabetização do PNLD/2010 do $1^{\circ}$ ano do ensino

\footnotetext{
${ }^{13}$ Embora pudesse ser excluído pelo critério dos anos de escolaridade, o trabalho de Nascimento continuou
} compondo nosso corpus, pelo fato dele ser o único selecionado por meio da palavra "leitura", em seu título. 
fundamental, para verificar o espaço dedicado ao ensino do sistema de escrita alfabética articulado com o letramento. Godinho (2014), por sua vez, foca no estudo das relações entre sons e letras e sua coerência ou inconsistência com a concepção de alfabetização anunciada pelos autores da obra. E, Araújo (2017) analisa o livro didático adotado em escolas públicas de Aracaju/SE, para saber como se introduz as letras vocálicas e consonantais, durante ensino e a aprendizagem iniciais de leitura para o letramento e cidadania.

Por outro lado, alguns autores, como Meneses (2010); Silva C. (2012); Teixeira (2014) buscam compreender o papel do livro didático de alfabetização e letramento na prática docente, observando os usos feitos pelos professores em salas de aula e as contradições e apropriações que emergem das orientações, prescrições e atividades previstas nesse material, no cotidiano escolar.

Apenas 02 trabalhos se dedicam à compreensão das concepções e representações, em discursos de alfabetização pelos autores e editores dos livros didáticos, como é o caso de Silva T. (2012), ou no campo da leitura, como vemos em Rodrigues (2018): “[...] neste estudo, o objetivo geral é analisar a concepção de leitura de um livro didático de língua portuguesa, do $2^{\circ}$ ano do Ensino fundamental I".

No corpus trabalhado por nós, foram encontrados apenas 06 trabalhos dedicados ao estudo da "leitura" dissociada da "escrita" ou do "ensino da literatura", aproximando-se do objeto de nosso interesse. São eles: Kikuchi (2010); Campos (2014); Albuquerque (2014); Luz (2015); Silva A. (2016) e Rodrigues (2018) que exploram ou questionam as atividades e questões postas nos livros didáticos para o desenvolvimento das habilidades de leitura e para a formação de leitores ou analisam e descrevem as estratégias de leitura que fundamentam as atividades com textos literários.

Esses estudos, em sua maioria, convergem para o entendimento da leitura como habilidades e competências a serem desenvolvidas por meio dos gêneros textuais, segundo orientações dos documentos oficiais, como os Parâmetros Curriculares de Língua Portuguesa (1998), ou a Base Nacional Curricular (BNCC, 2018). Albuquerque (2014), por exemplo, propõe analisar as estratégias de ensino utilizadas pelos docentes para a compreensão do texto e identificar as habilidades de leitura exploradas pelos docentes para a promoção da compreensão leitora. Luz (2015), por sua vez, reflete sobre atividades para a leitura e compreensão leitora em livros didáticos, para verificar se esses promovem o desenvolvimento de competências cognitivas para a depreensão do conteúdo implícito nos textos, para o uso de inferência, numa perspectiva da leitura como construção de sentidos e não mera decodificação.

Os livros didáticos analisados pelos pesquisadores tornam-se assim fontes de estudo para um conhecimento das práticas e dos usos desenvolvidos pelos professores na salas de aula e muitas vezes, eles apenas são citados como o material didático adotado para o trabalho pedagógico, como vemos nos trabalhos de Meneses (2010) e Stof (2010), entre outros. Outras vezes, são interrogados, como objeto de estudo, pelas concepções de alfabetização/letramento e de leitura em suas relações com as propostas didáticas disponíveis nesse material, ou ainda, pela identificação e exploração das estratégias de leitura necessárias à formação do leitor competente em suas diferentes situações de leitura.

No grupo das temáticas - "leitura e escrita na fase inicial da escolarização" ou "leitura como objeto de estudo dissociado da escrita" - não foi localizada nenhuma pesquisa que aborde a leitura como prática e o livro como objeto, culturalmente ressignificados em suas comunidades de leitores e possíveis de serem investigados pelos estudos trazidos pela História Cultural, conforme é nossa proposta de trabalho. 


\section{Uma terceira aproximação: vieses teóricos e metodológicos}

Quanto aos referenciais teóricos e metodológicos há um espalhamento por diferentes perspectivas, nem sempre explicitadas pelos pesquisadores, nos resumos de seus trabalhos.

Revendo pistas deixadas nos resumos pelos autores dos trabalhos, parece haver uma predominância pelo ensino da leitura (e escrita), na perspectiva cognitivista caracterizada pela presença das expressões como "estratégias", "competências", "habilidades" a serem desenvolvidas pelos alunos, conforme vemos em Silva A. (2016) e Albuquerque (2014). Mas há também indicações pela opção dos pesquisadores por uma abordagem socioconstrutivista, como é o caso de Meneses (2010) e de Luz (2015) que abordam a perspectiva da leitura (e escrita) como construção de sentidos e interação entre textos e leitores. Há ainda as pesquisas no campo da linguagem, pelo viés enunciativo - dialógico e constitutivo - com base nos estudos de M. Bakhtin, como as de Silva (2011); Rodrigues (2018) e Stof (2010), em que a linguagem como produção histórica e cultural se concretiza em gêneros discursivos. Em uma outra direção, apenas um único trabalho é mais marcado por uma perspectiva específica - o Sistema Scliar de Alfabetização (ARAÚJO, 2017). Alguns trabalhos em uma única referência mais explícita indicam a perspectiva teórica dos Estudos Culturais pós-estruturalistas e pósmodernos (SILVA T., 2012), ou o cunho documental que orienta os estudos das produções acadêmicas-científicas sobre a temática (GODINHO, 2014).

Outros pesquisadores (KIKUCHI, 2010; ANDRÉ, 2011; SILVA T., 2012; SILVA G., 2016) fazem referências explícitas a autores identificados pelo campo de estudos das práticas e das representações, que parecem se aproximar pela abordagem teórica e metodológica com o que pretendemos adotar em nossa pesquisa. O trabalho de Kikuchi (2010), por exemplo, apoiase na concepção da leitura como prática cultural citando Anne Marie Chartier. Da mesma forma, André (2011) e Silva G. (2016) apontam os autores Michel de Certeau e novamente Anne Marie Chartier como referenciais teóricos dos seus trabalhos.

Os resumos não indicam as opções metodológicas mais direcionalmente trabalhadas pelos pesquisadores. Alguns citam que as análises são de cunho qualitativo, justificando a seleção de um menor número de turmas ou de escolas, de um único livro ou coleção didática. Alguns estudos apontam uma abordagem comparativa entre turmas do $5^{\circ}$ ano do ensino fundamental de duas escolas da Rede Municipal de Recife, que adotaram o mesmo livro didático (LUZ, 2015). André (2011) declara que seu estudo é de natureza etnográfico e também constrói uma comparação entre os usos de dois distintos livros didáticos de alfabetização, Porta Aberta: Letramento e Alfabetização Linguística e uma apostila: Alfabetização Fônica: construindo competência de leitura e escrita, de um mesmo ano de escolaridade ( $1^{\circ}$ ano), por professoras em suas práticas pedagógicas no trabalho com atividades de leitura e de escrita (ANDRÉ, 2011).

As opções teóricas e metodológicas inferidas por nós ou explicitadas pelos pesquisadores nos resumos de suas pesquisas trazem vários aspectos importantes que envolvem o trabalho com a leitura (e escrita e literatura) pelo livro didático, mas ainda se distanciam da nossa opção feita pelos estudos trazidos pela História Cultural, com exceção do trabalho de Silva G. (2016) que indicou, no resumo de sua tese, trazer para as análises dos corpus de pesquisa o conceito de prática, ancorado no pensamento de Anne Marie Chartier.

\section{Uma quarta aproximação: pelas coleções estudadas pelos pesquisadores}

Os pesquisadores optam principalmente por livros didáticos que fazem parte do Programa Nacional do Livro Didático (PNLD) e especificam a que Coleções (seriadas para atender diferentes os anos escolares) esses livros fazem parte. Como já dissemos, em menor quantidade, 
os trabalhos analisam manuais dos professores ou as coleções aprovadas pelo PNLD 2016, triênios 2016, 2017 e 2018 para problematizar a escolarização do texto literário nos livros didáticos, como fez Silva A. (2016).

Entre as coleções indicadas pelos pesquisadores, localizamos apenas uma única vez a Coleção Aprender Juntos, da Editora SM (CAMPOS, 2014) e por duas vezes a L.E.R. Leitura, Escrita e Reflexão, como vimos em Nascimento (2012) e Silva C. (2012).

A Coleção Porta Aberta mostrou-se ser a mais recorrentemente indicada pelos pesquisadores. Foram 07 trabalhos em que seus autores (KIKUCHI, 2010; ANDRÉ, 2011; SILVA T., 2012; GODINHO, 2014; TEIXEIRA, 2014; ARAÚJO, 2017; RODRIGUES, 2018) analisaram livros didáticos que pertencem à Coleção Porta Aberta.

Tanto a Coleção Porta Aberta, quanto a L.E.R. são coleções da $F T D$, o que indicia uma significativa penetração dessa editora no mercado escolar. No entanto, essa preferência dos pesquisadores nos estudos sobre os livros didáticos de alfabetização/letramento e língua portuguesa da coleção Porta Aberta nos incita a levantar hipóteses. Seria por que essa Coleção é um dos materiais didáticos aprovado e mais bem posicionado no ranking do PNLD 2010?; é escolhido e adotado por várias redes de ensino brasileiros; e ainda, em 2010 há a implantação definitiva da nova estrutura do ensino fundamental de 9 anos, no sistema educacional do país e ela se adequa a este sistema?

A Coleção Ápis, objeto de estudo do nosso trabalho, aparece apenas no trabalho de Silva G. (2016) que observou os usos feitos deste material pelas professoras, nas salas de três turmas dos primeiros anos de escolaridade. Nesse sentido, a tese de doutorado intitulada Usos do livro didático de letramento e alfabetização pelos professores nos anos iniciais do ensino fundamental, de Silva G. (2016), nos interessa particularmente pela coincidência de escolha da mesma coleção e também pela aproximação com o referencial teórico indicado na pesquisa.

\section{Algumas considerações e questões a concluir}

Quando iniciamos a construção desta pesquisa bibliográfica, consultando o site do Catálogo de Teses e Dissertações da Capes, as finalidades foram conhecer o que os pesquisadores brasileiros vêm tematizando nos estudos do livro didático de língua portuguesa dos anos iniciais do ensino fundamental, para termos uma visão panorâmica do tema e compor uma pesquisa sobre a leitura significada entre representações e práticas no LDLP; ainda, estabelecer um diálogo com esses estudiosos das áreas de Educação e Letras que se propunham a estudar o LDLP e a leitura sob o enfoque teórico-metodológico da História Cultural.

Assim, o nosso levantamento bibliográfico foi mostrando investigações que têm por fonte ou documento o livro didático, mas nem sempre trazem em seus títulos o termo "leitura", compondo assim um critério para pertencer ao nosso corpus. Recorrendo aos seus resumos, verificamos que são trabalhos que se distanciam de nosso interesse maior de pesquisa, ora por tratar diretamente das práticas pedagógicas ou estratégias de leitura e de escrita (alfabetização) no primeiro ano, ora por estudar a "leitura" em uma perspectiva teórica distinta da que desejamos ancorar nosso olhar, ora ainda por serem livros didáticos de Língua Portuguesa, ou então, por não pertencerem à Coleção Ápis, nosso objeto de estudo.

Mas o levantamento nos ajudou a compor um conhecimento sobre as opções dos pesquisadores para vários aspectos que envolvem o trabalho com a leitura pelo livro didático, quer pelos usos feitos pelas professoras ou alunos, quer pelas representações e práticas nos discursos dos autores e editores do material didático, pelas estratégias ou habilidades que as atividades planejam intencionalmente incitarem ou ainda, pelas atividades metodológicas propostas por ele, e também pelo estudo focado no ensino e aprendizagem da leitura, nos primeiros anos de escolaridade, na especificidade do texto literário ou da preocupação com a formação de leitores. 
São trabalhos que permitem situar nosso interesse de forma mais circunstanciada no meio a um campo multidisciplinar, complexo e bastante diversificado quanto ao volume de livros didáticos lançados pelo mercado editorial, para usos no ambiente escolar e quanto ao olhar teórico e metodológico dos pesquisadores para a temática da leitura.

Por outro lado, esse pequeno volume formado por 21 trabalhos nos levou a considerar a relevância do nosso tema investigativo e de sua contribuição para o campo de estudos da leitura, do livro didático e do ensino de língua portuguesa do ensino fundamental I. O que torna o nosso objeto investigativo original, quando pretendemos estudar a leitura em suas práticas e representações significadas no LDLP dos anos iniciais sob a perspectiva da História Cultural.

\section{Referências}

ALBUQUERQUE, R. K. de. Os acervos complementares do PNLD como recursos didáticos para o ensino da leitura. 2014. Dissertação (Mestrado em Educação) - Centro de Educação, Universidade Federal de Pernambuco, Recife, 2014. Disponível em: https://catalogodeteses.capes.gov.br/catalogoteses/\#!/. Acesso em: 17 abr. 2020.

ANDRÉ, T. C. Usos do livro didático de alfabetização no primeiro ano do ensino fundamental em Foz do Iguaçu: estudo etnográfico. 2011. Tese (Doutorado em Educação) - Universidade Federal do Paraná, Curitiba, 2011. Disponível em: https://acervodigital.ufpr.br/handle/1884/27323. Acesso em: 17 abr. 2020.

ARAUJO, C. M. de. Ensino da leitura: como as letras são introduzidas no livro didático Porta Aberta - 1. ${ }^{\circ}$ ano. 2017. Dissertação (Mestrado em Letras) - Fundação Universidade Federal de Sergipe, 2017. Disponível em: http://catalogodeteses.capes.gov.br/catalogo-teses/\#!/. Acesso em: 17 abr. 2020.

BAKHTIN, M. Estética da criação verbal. Introdução e tradução de Paulo Bezerra; prefácio à edição francesa de Tzvetan Todorov. 4. ed. São Paulo: Martins Fontes, 2003.

BARROS, J. D' A. O campo da história: especialidades e abordagens. 4. ed. Petrópolis, RJ: Vozes, 2004.

BATISTA, A. A. G. Alfabetização, leitura e ensino de português: desafios e perspectivas curriculares. Revista Contemporânea de Educação, n. 12, ago./dez., v. 6, 2011. p. 246-272. Disponível em: https://revistas.ufrj.br/index.php/rce/article/view/1638. Acesso em: 06 set. 2019.

BATISTA, A. A. G. Um objeto variável e instável: textos, impressos e livros didáticos. In: ABREU, Márcia (Org.). Leitura, história e história da leitura. 2. ${ }^{a}$ reimp. Campinas, SP: Mercado de Letras: Associação de Leitura do Brasil; São Paulo: Fapesp, 2007. p. 529.

BATISTA, A. A. G. Sobre a leitura: notas para a construção de uma concepção de leitura de interesse pedagógico. Em Aberto, Brasília, ano 10, n. 52, out./dez. 1991.

BITTENCOURT, C. M. F. Livro didático e conhecimento histórico: Uma história do saber escolar. 1993. Tese (Doutorado em História Social) - Faculdade de Filosofia, Letras e Ciências Humanas, Universidade de São Paulo, São Paulo, 1993. 
BUNZEN, C. Dinâmicas discursivas nas aulas de português: os usos do livro didático e projetos didáticos autorais. 2009. Tese (Doutorado em Linguística Aplicada) - Instituto de Estudos da Linguagem, Universidade Estadual de Campinas, Campinas, 2009.

BUNZEN, C. Livro didático de língua portuguesa: um gênero do discurso. 2005. Dissertação (Mestrado em Linguística Aplicada) - Instituto de Estudos da Linguagem, Universidade Estadual de Campinas, Campinas, 2005.

CAMPOS, N. K. de S. Práticas de ensino para a formação do leitor: o uso do livro didático e a exploração das estratégias de leitura no 1. ${ }^{\circ}$ ano do ensino fundamental. 2014. Dissertação (Mestrado em Educação) - Centro de Educação, Universidade Federal de Pernambuco, Recife, 2014. Disponível em: https://catalogodeteses.capes.gov.br/catalogo-teses/\#!/. Acesso em: 17 abr. 2020.

CHARTIER, R. A história cultural: entre práticas e representações. Lisboa: Difel, 1990.

FERREIRA, N. S. de A. O escritor da pena feiticeira: João Köpke (1852- 1926). Educ. Pesqui., São Paulo, v. 44, e161585, 2018. Disponível em: http://www.scielo.br/scielo.php?script=sci_arttext\&pid=S151797022018000100413\&lng=pt\&nrm=iso. Acesso em: 10 set. $2019 . \quad$ Epub 05-Out-2017. http://dx.doi.org/10.1590/s1678-4634201709161585.

FERREIRA, N. S.; SILVA, L. L. M. Contribuições para história da leitura no Brasil: elementos de dissertações de Mestrado e teses de Doutorado. In: Maria do Rosário Longo Mortatti. (Org.). Alfabetização no Brasil: uma história de sua história. São Paulo: Cultura Acadêmica, 2011. p. 142-161. Disponível em: isihele.indd (unesp.br). Acesso em: 19 jan. 2021.

FERREIRA, N. S. As pesquisas denominadas "estado da arte". Educ. Soc., Campinas, v. 23, n. 79, p. 257-272, ago. 2002. Disponível em: http://www.scielo.br/scielo.php?script=sci_arttext\&pid=S010173302002000300013\&lng=en\&nrm=iso. Acesso em: 27 maio 2020.

FERREIRA, N. S. Pesquisa em Leitura: um estudo dos resumos de dissertações de mestrado e teses de doutorado defendidas no Brasil, de 1980 a 1995. 1999. Tese (Doutorado em Educação) - Faculdade de Educação, Campinas, 1999.

FERREIRA, N. S. Leitura de histórias de leitura. 1994. Dissertação (Mestrado em Educação) - Faculdade de Educação, Campinas, 1994.

GODINHO, R. dos S. As relações sons e letras/letras e sons em livros didáticos de alfabetização (PNLD 2010): limitações e desafios ao encontro de uma abordagem discursiva de linguagem. 2014. Tese (Doutorado em Educação) - Centro de Educação, Universidade Federal do Espírito Santo, Vitória, 2014. Disponível em: https://catalogodeteses.capes.gov.br/catalogo-teses/\#!/. Acesso em: 17 abr. 2020.

KIKUCHI, F. L. A importância das atividades prescritas pelo livro didático e pelo professor para a formação de leitores. 2010. Dissertação (Mestrado em Educação) - Centro de Educação, Comunicação e Artes, Universidade Estadual de Londrina, Londrina, 2010. Disponível em: http://catalogodeteses.capes.gov.br/catalogo-teses/\#!/. Acesso em: 17 abr. 2020. 
LIMA, H. K. C. de. A formação do professor de português e o livro didático: reflexões sobre documentos, discursos e práticas. 2015. Tese (Doutorado em Educação) - Centro de Educação, Universidade Federal de Pernambuco, Recife, 2015. Disponível em: https://catalogodeteses.capes.gov.br/catalogo-teses/\#!/. Acesso em: 17 abr. 2020.

LUZ, M. A. S. da. A inferência no livro didático de língua portuguesa do 5. ${ }^{o}$ ano. 2015. Dissertação (Mestrado Profissional em Letras). Centro de Educação, Universidade Federal de Pernambuco, 2015. Disponível em: http://catalogodeteses.capes.gov.br/catalogo-teses/\#!/. Acesso em: 17 abr. 2020.

MACIEL, F. I. P. Lúcia Casasanta e o método global de contos: uma contribuição à história da alfabetização em Minas Gerais. 2001. Tese (Doutorado em Educação) - Faculdade de Educação, Universidade Federal de Minas Gerais, Belo Horizonte, 2001. Disponível em: http://hdl.handle.net/1843/FAEC-86PRY6. Acesso em: 19 jan. 2021.

MENEZES, E. de M. P. L. Ensino de leitura e escrita: entre reclamações e apoio pedagógico. 2010. Dissertação (Mestrado em Educação) - Instituto de Educação, Universidade Federal de Mato Grosso, Cuiabá, 2010. Disponível em: http://catalogodeteses.capes.gov.br/catalogoteses/\#!/. Acesso em: 17 abr. 2020.

MOREIRA, K. H. Pesquisas em História da Educação com o livro didático: questões sobre fontes, temas e métodos. Revista de Educação Pública, v. 26, n. 63, p. 877-903, set./dez. 2017. ISSN 2238-2097. Disponível em: http://periodicoscientificos.ufmt.br/ojs/index.php/educacaopublica/article/view/2266. Acesso em: 17 abr. 2020. doi: http://dx.doi.org/10.29286/rep.v26i63.2266.

MOREIRA, K. H. Livros didáticos como fonte de pesquisa: um mapeamento da produção acadêmica em História da Educação. Educação e Fronteiras, Dourados, v. 2, n. 4, p. 129-142, fev. 2012. ISSN 2237-258X. Disponível em: http://ojs.ufgd.edu.br/index.php/educacao/article/view/1562. Acesso em: 17 abr. 2020.

MOREIRA, K. H. Livros didáticos como fontes para a história da educação: um mapeamento da produção acadêmica. CONGRESSO BRASILEIRO DA HISTÓRIA DA EDUCAÇÃO, 4., 2011. Anais... Vitória, ES, maio. 2011. Disponível em: http://www.sbhe.org.br/novo/congressos/cbhe6/anais_vi_cbhe/conteudo/res/trab_1209.htm.

Acesso em: 17 de abr. 2020.

MORTATTI, M. do R. L.; OLIVEIRA, F. R. de; PASQUIM, F. R. 50 anos de produção acadêmica brasileira sobre alfabetização: avanços, contradições e desafios. Interfaces da Educ., Paranaíba, v. 5, n. 13, p. 06-31, 2014. ISSN 2177-7691. Disponível em: https://periodicosonline.uems.br/index.php/interfaces/article/view/482/448. Acesso em: 26 abr. 2020.

MORTATTI, M. do R. L. (Org.). Alfabetização no Brasil: uma história de sua história. São Paulo: Cultura Acadêmica; Marília: Oficina Universitária, 2011. p. 142-161. Disponível em: isihele.indd (unesp.br). Acesso em: 19 jan. 2021.

MORTATTI, M. do R. L. História dos métodos de alfabetização no Brasil. Conferência parte do Seminário "Alfabetização e letramento em debate". Departamento de Políticas Públicas de Educação Infantil e Ensino Fundamental da Secretaria de Educação Básica do Ministério da Educação. Brasília, em 27.04.2006. 
Disponível em: http://portal.mec.gov.br/seb/arquivos/pdf/Ensfund/alf_mortattihisttextalfbbr.pdf. Acesso em: 30 jul. 2020.

MORTATTI, M. do R. L. Os sentidos da alfabetização: São Paulo - 1876/1994. São Paulo: Editora Unesp, 2000. E-book.

MUNAKATA, K. O livro didático: alguns temas. Rev. bras. hist. educ., Campinas-SP, v. 12, n. 3 (30), p. 179-197, set./dez. 2012. Disponível em: http://doi.editoracubo.com.br/10.4322/rbhe.2013.008. Acesso em: 22 abr. 2020.

MUNAKATA, K. Produzindo livros didáticos e paradidáticos. 1997. Tese (Doutorado em História e Filosofia da Educação) - Pontifícia Universidade Católica de São Paulo, São Paulo, 1997.

NASCIMENTO, M. M. do. Leitura no livro didático português: linguagens possibilidades emancipadoras. 2017. Dissertação (Mestrado em Educação) - Unidade Acadêmica de Humanidades, Ciências e Educação, Universidade do Extremo Sul Catarinense, Criciúma, 2017. Disponível em: https://catalogodeteses.capes.gov.br/catalogo-teses/\#!/. Acesso em: 05 maio 2020.

NASCIMENTO, R. O. do. O livro didático de alfabetização na era do letramento: uma análise crítica. 2012. Dissertação (Mestrado em Letras) - Universidade do Estado do Rio de Janeiro, Rio de Janeiro, 2012. Disponível em: http://catalogodeteses.capes.gov.br/catalogo-teses/\#!/. Acesso em: 05 maio 2020.

RODRIGUES, P. T. O trabalho com a leitura no livro didático do $2 .^{\circ}$ ano do ensino fundamental I: uma análise das questões de interpretação do gênero conto. 2018. Dissertação (Mestrado em Educação) - Programa de Pós-Graduação Stricto Sensu em Educação, Universidade São Francisco, Itatiba, 2018. Disponível em: https://catalogodeteses.capes.gov.br/catalogo-teses/\#!/. Acesso em: 05 maio 2020.

ROJO, R. R. Letramentos escolares: coletâneas de textos nos livros didáticos de língua portuguesa. Perspectiva - Revista do Centro de Ciências da Educação, UFSC, Florianópolis, v. 28, n. 2, 2010. Disponível em: https://periodicos.ufsc.br/index.php/perspectiva/article/view/2175-795X.2010v28n2p433. doi: https://doi.org.10.5007/2175-795X.2010v28n2p433. Acesso em: 21 abr. 2020.

ROJO, R.; BATISTA, A. A. G. (Org.). Livro didático de língua portuguesa, letramento e cultura da escrita. Campinas: Mercado de Letras, 2003.

SILVA, A. R. S. Escolarização do texto literário no livro didático de língua portuguesa (PNLD 2016). 2016. Dissertação (Mestrado em Educação) - Programa de Pós-Graduação em Educação, Universidade Federal do Rio Grande do Norte, Natal, 2016. Disponível em: https://catalogodeteses.capes.gov.br/catalogo-teses/\#!/. Acesso em: 05 maio 2020.

SILVA, C. V. do A. e. O livro didático de alfabetização: o manual do professor e sua relação com o fazer pedagógico referente ao ensino de leitura e escrita. 2012. Dissertação (Mestrado em Educação) - Centro de Educação, Universidade Federal de Pernambuco, Recife, 2012. Disponível em: http://catalogodeteses.capes.gov.br/catalogo-teses/\#!!. Acesso em: 05 maio 2020. 
SILVA, G. M. da. Usos do livro didático de letramento e alfabetização pelos professores nos anos iniciais do ensino fundamental. 2016. Tese (Doutorado em Educação) - Faculdade de Educação, Universidade Federal de Minas Gerais, Belo Horizonte, 2016. Disponível em: https://catalogodeteses.capes.gov.br/catalogo-teses/\#!/. Acesso em: 05 maio 2020.

SILVA, J. B. da. (Re) descobrindo o prazer da leitura: uma interação entre teoria e prática em sala de aula. 2011. Dissertação (Mestrado em Letras) - Universidade do Estado do Rio de Janeiro, Rio de Janeiro, 2011. Disponível em: http://catalogodeteses.capes.gov.br/catalogoteses/\#!/. Acesso em: 05 maio 2020.

SILVA, J. G. B. e. Os gêneros jornalísticos nos livros didáticos de $5^{\circ}$ e $6^{\circ}$ ano do ensino fundamental. 2014. Dissertação (Mestrado em Educação) - Programa de Pós-Graduação Stricto Sensu em Educação, Universidade São Francisco, Itatiba, 2014. Disponível em: https://catalogodeteses.capes.gov.br/catalogo-teses/\#!/. Acesso em: 05 maio 2020.

SILVA, T. da. Os "novos" discursos sobre alfabetização em análise: os livros de $1^{\circ}$ ano do ensino fundamental de nove anos do Programa Nacional do Livro Didático (PNLD 2010). 2012. Tese (Doutorado em Educação) - Universidade Federal do Rio Grande do Sul, Porto Alegre, 2012. Disponível em: http://bdtd.ibict.br/vufind/Search/Results?lookfor=SILVA\%2C+THAISE+DA\&type=AllFields\&limit=20 \&sort=relevance. Acesso em: 05 maio 2020.

SOUZA, B. S. A. de. As práticas de leitura e escrita: a transição da educação infantil para o primeiro ano do ensino fundamental. 2011. Dissertação (Mestrado em Educação) - Centro de Educação, Universidade Federal de Pernambuco, Recife, 2011. Disponível em: http://catalogodeteses.capes.gov.br/catalogo-teses/\#!/. Acesso em: 05 maio 2020.

STOLF, J. Práticas sociais de leitura e escrita no primeiro ano do ensino fundamental: um estudo de caso. 2010. Dissertação (Mestrado em Educação) - Universidade Regional de Blumenau, Blumenau, 2010. Disponível em: http://catalogodeteses.capes.gov.br/catalogoteses/\#!/. Acesso em: 05 maio 2020.

TEIXEIRA, R. de F. B. Livro didático de alfabetização: o ponto de vista da pesquisa acadêmica. In: CONGRESSO NACIONAL DE EDUCAÇÃO-EDUCERE, 11. SEMINÁRIO INTERNACIONAL DE REPRESENTAÇÕES SOCIAIS, SUBJETIVIDADE E EDUCAÇÃO-SIRSSE, 2. SEMINÁRIO INTERNACIONAL SOBRE PROFISSIONALIZAÇÃO DOCENTE-SIPD/CÁTEDRA UNESCO, 4. Anais... Pontifícia Universidade Católica do Paraná, Curitiba, PR, 2013. (23 a 26.09.2013). Disponível em: https://educere.bruc.com.br/arquivo/pdf2013/10053_6664.pdf. Acesso em: 30 jul. 2020.

TEIXEIRA, R. de F. B. As práticas cotidianas de alfabetização e o livro didático: um estudo etnográfico. 2014. Tese (Doutorado em Educação) - Programa de Pós-graduação em Educação, Setor de Educação, Universidade Federal do Paraná, Curitiba, 2014. Disponível em: https://sucupira.capes.gov.br/sucupira/public/consultas/coleta/trabalhoConclusao/viewTrabalh oConclusao.jsf?popup=true\&id_trabalho=177409. Acesso em: 20 jul. 2020. 


\section{Sobre a autora}

Maria de Fátima Xavier da Anunciação de Almeida. Pós-doutoranda em Educação/Depto. DELART - FE/UNICAMP. Doutora em Letras/Universidade Presbiteriana Mackenzie; Mestre em Educação/UFMS. Professora Adjunta do Curso de Pedagogia da Faculdade de Educação/Universidade Federal de Mato Grosso do Sul. Participa dos Grupos de Estudos e Pesquisas ALLEAULA/UNICAMP e GEPEH/UFMS.

E-mail: maria.almeida@ufms.br. 